\title{
Sulu Çözeltideki Bor İyonlarının Sepiyolit İle Giderimi
}

\author{
Tuğba ARIKAN(D) \\ Kahramanmaraş Sütçü İmam Üniversitesi Eğitim Fakültesi, Kahramanmaraş \\ https://orcid.org/0000-0002-5644-9515 \\ $\bowtie:$ tatilan76@hotmail.com
}

\section{ÖZET}

Türkiye'de sulama sularını en fazla kirleten toksik elementlerin başında bor bulunmaktadır. Endüstriyel işlemler sonucunda ortaya çıkan ağır metaller toprak, su ve atmosfere karışarak canlı organizmaların yaşamını etki altında bırakmakta ve çevre kirliliğine sebep olmaktadır. Biyolojik olarak parçalanıp yok olmadıklarından dolayı organizmalarda depolanan ve besin zincirlerine giren atık sulardaki ağır metal iyonları, birtakım işlemlere tabi tutularak standartlara uygun hale getirilmelidir. Bu çalışmada, Eskişehir yöresinden alınan sepiyolitin, çalışma koşullarına bağlı olarak, sulu çözeltilerdeki bor (III) iyonlarını adsorplama kapasitesi araştırılmıştır. $\mathrm{Bu}$ amaçla, borik asit çözeltisi kullanılarak bor iyonunun adsorpsiyonu ve adsorpsiyon olayını etkileyen $\mathrm{pH}$, adsorban miktarı gibi değişkenlerin adsorpsiyon kapasitesi üzerindeki etkileri belirlenmiştir. Deney sonuçları, çözelti $\mathrm{pH}$ değerinin arttıkça adsorplanan bor miktarının arttığını göstermiştir. Adsorpsiyon verimi (\%), adsorban miktarının artması ile belirli bir adsorban miktarına kadar artmış, belirli bir değerden sonra ise büyük bir değişime sebep olmamıştır. İstatistiksel olarak değerlendirme yapıldığında adsorpsiyon kapasitesi üzerinde en önemli değişkenin adsorban madde miktarı olduğu saptanmıştır.

\section{Removal of Boron Ions in Aqueous Solution by Sepiolite}

\section{ABSTRACT}

In our country, boron is one of the toxic elements that pollute irrigation water mostly. Heavy metals, which arise as a result of industrial processes, cause environmental pollution and interfere living life by contaminating water, soil and atmosphere. Heavy metal ions in wastewater are stored in organisms and enter into food chains because they are not biodegradable. For this reason, polluted wastewater released after industrial activities should be subjected to various processes and should be adjusted to standards. In this study, the change of adsorption capacity of boric (III) ions of aqueous sepiyolite from Eskişehir region was investigated. For this purpose, the effect of boron ion adsorption on the adsorption capacity of the boron ion and the effect of adsorption on the adsorption capacity of the parameters such as $\mathrm{pH}$ were determined. The test results showed that the amount of boron in the solution increased as with the $\mathrm{pH}$ of the solution increased. With the increase in the amount of adsorbent, the adsorption efficiency (\%) continues to increase to a certain level of adsorbent and after a certain value the addition of adsorbent did not cause a significant change. As a result of the statistical evaluation, the most effective parameter on the adsorption capacity was the amount of adsorbent.

\section{Araştırma Makalesi}

Makale Tarihçesi

Geliş Tarihi $\quad: 17.12 .2018$

Kabul Tarihi : : 18.01.2019

\section{Anahtar Kelimeler}

Adsorpsiyon

Sepiyolit

Bor

\section{Research Article}

$\begin{array}{ll}\text { Article History } & \\ \text { Received } & : 17.12 .2018 \\ \text { Accepted } & : 18.01 .2019\end{array}$

\section{Keywords}

Adsorption

Sepiolite

Boron

To Cite : Arıkan T 2019. Sulu Çözeltideki Bor İyonlarının Sepiyolit İle Giderimi. KSÜ Tarim ve Doğa Derg 22(2): 333-338. DOI: 10.18016/ksutarimdoga.v22i42694.498284 


\section{GİRIŞ}

Bor, bütün besin elementleri içerisinde, toksik etki yapan miktarı ile eksiklik belirtilerine neden olan miktarı, birbirine çok yakın olan tek elementtir. Aynı zamanda, farklı amaçlar ile kullanılabilen yeryüzünde yüzden fazla minerali bulunan bir elementtir (Çalık, 2002). Bor; gübre, ilaç, kimya, otomobil sanayisi gibi çok fazla alanda kullanılmakta ve bilim adamları borun gelecekte beyaz petrol olacağını belirtmektedirler (Çalık, 2004). Türkiye bor mineral rezervlerinin çeşitliliği, kalitesi ve büyüklüğü açısından dünyada birinci sırada bulunmaktadır. Dünyadaki bor rezervlerinin \%72'sinden fazlası Türkiye'de bulunmaktadır (Kayadan ve ark., 2004). Madenlerin işletilmesi sırasında çıkan atıklar, su ve toprak kirlenmesine neden olmaktadır. Türkiye'de sulamada kullanılan suyun kirlenmesine neden olan toksik elementlerin başında bor bulunmaktadır. Endüstri atıklarında bor derişimi limit değerlerinin üzerine çıktığı zaman, tarımsal sulamada kullanıldığında, bitkilere veya suda yaşayan canlılara zarar vermektedir. Diğer yandan da bazı metabolik faaliyetler için sulama suyunda kesinlikle bor bulunmalıdır. Meyve ve sebzelerin yetiştirilmesinde gerekli bir eser elementtir. $\mathrm{Bu}$ nedenle sulama suyunda ve toprakta bulunan bor miktarı, ürünlerin yetiştirilmesinde ve kalitesinde önemli bir rol oynar (Brown ve ark., 2002).

Bor, hidrosfer ve litosfere dağılmış yaygın olarak bulunan bir iz elementtir. Litosferde, toprakta veya kayalarda bulunan borun yerkabuğundaki ortalama konsantrasyonu $10 \mathrm{mg} \mathrm{kg-1'dır} \mathrm{ve} \mathrm{dünyadaki} \mathrm{element}$ bileşiminin sadece \% 0.001'ini oluşturur. Hidrosferde, deniz suyundaki ortalama konsantrasyonu $4.5 \mathrm{mg} \mathrm{L}^{-1}$ iken, yeraltı suyundaki konsantrasyonu $0.3 \mathrm{mg} \mathrm{L}^{-1}$ ile $100 \mathrm{mg} \mathrm{L}^{-1}$ arasında değişmektedir (Zhimin ve ark., 2016).

Rainey ve ark. (1999)'na göre normal bir insan günde yaklaşık olarak $1 \mathrm{mg}$ bor almalıdır ve normal besin tüketimi bu miktarı sağlayabilmektedir. Bu nedenle bu element için ek bir kaynağa gerek duyulmamaktadır. Günlük beslenmemizle sebze ve meyvelerden günde 10-20 mg kadar bor vücudumuz tarafindan alınmaktadır. Priscilla (1998) yiyecek ve içecekler ile vücudumuza alınan borun \%90‘dan fazlası idrarla atılırken, geri kalan kısmı saç, kemik, dişler, tırnak, dalak ve karaciğer gibi vücudumuzun türlü kısımlarında biriktiğini söylemiştir. Dünya Sağlık Örgütü 2000 yılında bor içeriğinin üst sınırını içme suları için $0.3 \mathrm{mg} \mathrm{L}^{-1}$ olarak saptamıştır (WHO, 2003). Fort ve ark. (1999) omurgalı hayvanların embriyolarının gelişiminde borun çok önemli olduğunu, borun yetersiz kaldığ durumlarda ise gelişim bozukluklarının ortaya çıtığını göstermişlerdir. Bai ve Hunt (1996) beslenmeyle ilgili yapmış oldukları çalışmalarda kemik metabolizması üzerine borun oldukça faydalı olduğunu belirtmişlerdir.

Hunt (2003) ise gidalarda bulunan borun organizmaların bağışıklık sistemlerini etkilediği söylemektedir. Bor, doğada borat (borik asit tuzu), borik asit, ya da borosilikat mineralleri halinde bulunmaktadır. Holleman ve Wiberg (2001) bor'un bütün tuzlarının elektron alıcı olduğunu ifade etmiştir. $\mathrm{Bu}$ nedenle Borik asit, $\mathrm{H}_{3} \mathrm{BO}_{3}$ (veya $\mathrm{B}(\mathrm{OH})_{3}$ ), sulu çözeltilerde zayıf Lewis asidi davranışı sergiler (Power ve Woods 1997). Suda bulunan hidroksit iyonlarını alarak çözeltiye proton verir. Denge denklemi ise aşağıda verilmektedir (Dean, 1987).

$\mathrm{B}(\mathrm{OH})_{3}+\mathrm{H}_{2} \mathrm{O} \Leftrightarrow \mathrm{B}(\mathrm{OH})_{4^{-}}+\mathrm{H}^{+}\left(\mathrm{Ka}=5.8 \times 10^{-10} ; \mathrm{pKa}\right.$ $=9.24 ; 25^{\circ} \mathrm{C}$ )

Borik asit dissosiyasyonu $\mathrm{pH}^{\prime} \mathrm{in}$ bir fonksiyonudur. pH 9.24'den düşük olduğunda yüklü olmayan türler daha fazla iken $\mathrm{pH}$ 9.24 ün üzerinde çözeltide $\mathrm{B}(\mathrm{OH})_{4}$ anyonu daha fazladır. Borik asit suda çözünebilmektedir ve çözünebilirliği sıcaklık artışıyla artmaktadır (5.75 g $\mathrm{H}_{3} \mathrm{BO}_{3} / 100 \quad \mathrm{~g} \quad \mathrm{H}_{2} \mathrm{O}, \quad 25{ }^{\circ} \mathrm{C}$ ) (Waggott, 1969).

pH değeri yüksek olan topraklarda, borun adsorbsiyonu hizlı bir şekilde olduğundan, bu topraklarda bor miktarı eksiktir. Ortamın $\mathrm{pH}^{`} 1$ 6.3-6.5 olduğunda bor alımı en yüksek seviyeye ulaşmaktadır. Bor içeriği zengin topraklardaki bor kirliliğinin nedeni, içerisinde fazla miktarda bor bulunduran gübre, atık ve uçucu kül nedeniyle veya bor kirliliğine uğramış sulama sularıyla sulanan topraklarda meydana gelmektedir (Nable ve Banuelos, 1997). Bitkilerin bor içeriğine karşı hassasiyetleri farklıdır. Bazı bitkiler sulama sularındaki en çok $0.3 \mathrm{mg} \mathrm{L}^{-1}$ bor miktarına dayanabilmekteyken; bazıları ise $4 \mathrm{mg} \mathrm{L}^{-1}$ bor miktarma dayanabilmektedir (Keren ve Bingham, 1985). Hayvanlar için öldürücü borik asit miktarı, hayvanın cinsine göre değişmekle birlikte kg başına1.2 - $3.45 \mathrm{~g}$ arasındadır. Uygan ve Çetin (2004) hayvanlar için kullanılan suda $2.5 \mathrm{~g} \mathrm{~L}^{-1}$ borik asit bulunmasının büyümeyi engellediğini, bu nedenle zararlı olduğunu ifade etmiştir. Ayrıca hayvanlarda, bor ile ilişkili ana toksik etki, üreme sistemini içerir. Bor fazlalılığı, sıçanlarda, farelerde ve köpeklerde erkek üreme sisteminde spesifik yan etkilere neden olarak, germ hücrelerinin yokluğu veya kaybı ile sonuçlanmıştır. Bor, dişi farelerde böbrek lezyonlarina ve ovulasyonda azalmaya neden olmuştur (Fail PA ve ark. 1998).

İçme sularındaki borun varlığı genellikle canlılar için zararlı olarak belirtilmektedir. Türkiye'deki $\mathrm{Su}$ Kirliliği Kontrolü Yönetmeliğínde, içilecek su olarak öngörülen kullanılabilecek 1 . kalite suda borun olması gereken maksimum miktarı $1 \mathrm{mg} \mathrm{L}$-1 $^{1}$ dir. İçme suları için Dünya Sağlık Örgütü'nün belirttiği değer ise $0.3 \mathrm{mg} \mathrm{L}^{-1 ‘}$ dir. Bu nedenle içerisinde bor bulunan atık suların, doğaya salınabilmesi için, belirlenen 
değere getirilmesi gereklidir. Sulu çözeltilerden borun uzaklaştırılması için farklı metotlar bulunmaktadır. Bunlar oldukça geniş uygulama alanı olan ekstraksiyon, ters osmoz, elektrodiyaliz ve adsorpsiyon metotlarıdır (Xu ve Jiang, 2008).

Atık sularda ortaya çıkan ağır metallerin adsorpsiyon yöntemiyle uzaklaştırılması, adsorbanın türüne bağlı olarak diğer metotlara oranla daha etkin ve ekonomik bir yöntemdir. Ağır metalin uzaklaştırılmasında en etkin ve verimli metot olan adsorpsiyon, ara yüzeylerde gerçekleşen iki fazı birbirinden ayıran tutunma olayı olarak belirtilmektedir. Ağır metal iyonlarını adsorplamada yaygın olarak kullanılan kil mineralleri, mekanik ve kimyasal kararlılıkları, yapısal özellikleri, düşük maliyetleri, yüksek yüzey alanları sebebiyle sulu çözelti içerisindeki ağır metal iyonlarını adsorplamada çokça kullanılmaktadır.

Adsorpsiyonda ucuz sorbent arayışı nedeniyle sepiyolitin ağır metal iyonlarını tutabilme özelliği araştırılmıştır. Sepiyolit; magnezyum hidrosilikatten ibaret fillosilikatler (tabakalı silikatler) grubuna aittir. Kristal morfolojisi ve kompozisyonu, lifsi yapısı, yüksek yüzey alanı, porozitesi gibi özelliklerinden ötürü geniş bir kullanım alanında yer almaktadır. Sepiyolit; baca gazlarının temizlenmesinde, kauçuk ve ilaç sanayisinde, endüstriyel atık suların arıtılmasında, hayvancılık, tarım ve besicilikte kullanılmaktadır. Sepiyolit, içerisinde zeolitik su ve diğer molekülleri barındırabilecek kanallar bulunması nedeniyle, doğal haliyle bile, oldukça yüksek adsorplama kapasitesine sahiptir; kendi ağırlı̆̆ının 2-2.5 katı kadar su tutabilmektedir. Ayrıca sepiyolit, doğal haliyle, ısıl aktivasyona tabi tutularak ya da asit aktivasyon işlemine tabi tutularak adsorban olarak kullanılabilmektedir. Isıl aktivasyon işleminde yüzey alanı önemli ölçüde azalmaksızın higroskobik ve zeolitik su uzaklaştırılmakta dolayısıyla adsorban kapasitesi artmaktadır. Asit aktivasyon işleminde ise mineraldeki safsızlıkların ve metal katyonların proton ile yer değiştirerek uzaklaştırılması sepiyolitin yüzey alanı ve asidik merkez sayısını arttırmaktadır (Sabah ve Çelik, 1998). Yapılan çalışmalarda, düşük konsantrasyonlarda ki ağır metalleri sepiyolit belirgin bir kapasitesiteyle adsorblayabilmektedir. Nagy ve Bradley, (1955)'ın tanımına göre, sepiyolitin kimyasal formülü, $\quad \mathrm{Si}_{12} \mathrm{Mg}_{9} \mathrm{O}_{30}(\mathrm{OH})_{6}\left(\mathrm{OH}_{2}\right)_{4} \cdot 6 \mathrm{H}_{2} \mathrm{O}$ olarak verilmişken

Brauner ve Preisinger, (1956)' $1 n$ modeline göre ise

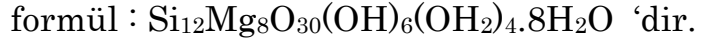

Öztürk ve Köse (2008), Dowex 2X8 reçinesini kullanarak sıvı çözeltilerden bor gideriminin etkisini araştırmışlardır. Bor gideriminde adsorpsiyon süresi, $\mathrm{pH}$, başlangıç bor derişimi, adsorban miktarı ve sıcaklığın etkilerini incelemişlerdir. $\mathrm{pH}=9$ 'da maksimum bor giderimi gözlenmiştir. Sicaklığın ve başlangıç bor iyonu derişiminin artmasıyla bor giderim yüzdesi azalmış, adsorban miktarının artması ile ise bor giderim yüzdesini artmıştır.

Çengeloğlu ve ark. (2007), nötralize kırmızı çamurla sıvı çözeltilerden bor giderimini çalışmışlardır. Adsorpsiyon süresi, $\mathrm{pH}$ ve adsorban miktarının etkilerini araştırmışlardır. Deneyler, adsorban miktarının artmasıyla bor gideriminin arttığını göstermiştir.

Adsorbatın çözeltide hangi formda olacağını ortamın $\mathrm{pH}$ değeri belirlemektedir. Moleküller belirli $\mathrm{pH}$ aralığında bir çözücüde çözünürken bu aralığın dışına çıkıldığında çökebilmektedirler. Bunun dışında $\mathrm{pH}$ adsorbanın yüzey fonksiyonel gruplarına da etki ederek, adsorpsiyon kapasitesine tesir etmektedir (Yingkai ve Lan, 2001).

$\mathrm{Bu}$ çalışmada, sulu çözeltideki bor iyonlarının adsorpsiyon yoluyla giderilmesi ve adsorpsiyona etki eden faktörler incelenmiştir. Bu çalışmada, Eskişehir yöresinden alınmış sepiyolitin, sulu çözeltilerdeki bor (III) iyonlarını giderimi araştırılmıştır. Bu nedenle, optimum çözelti pH'sının ve adsorban miktarının adsorplama kapasitesine olan etkileri araştırılmış ve elde edilen sonuçların değerlendirilmesi yapılmıştır.

\section{MATERYAL ve METOT}

Deneylerde, ortalama olarak porozitesi \% 70 olan Eskişehir-Sivrihisar yöresinin kahverengi sepiyoliti adsorban olarak kullanılmıştır. Sepiyolite sırasıyla kırma, öğütme ve eleme işlemleri yapılmıştır. Başlangıçta deiyonize su ile yıkanmış, süzgeç kağıdından süzülmüş, sonrasında ise ısıl aktivasyon işlemi uygulanmıştır. Sepiyolit numunesi $400^{\circ} C^{\prime} y e$ ısıtılmış firında 6 saat bekletilerek aktive edilmiş, daha sonra desikatörde vakum altında kademeli olarak soğuması sağlanmıştır. Isıl aktive edilen sepiyolit numunesi tamamen ağzı kapalı bir kapta karanlık bir mekanda muhafaza edilmiştir.

Deney çözeltilerinin hazırlanmasında Merck firmasindan alınan $\mathrm{H}_{3} \mathrm{BO}_{3}$ 'den hazırlanan 1000 ppm'lik stok çözelti ve bu stok çözeltinin seyreltilmesiyle hazırlanan farklı derişimlerdeki çözeltiler kullanılmıştır. Adsorpsiyon deneylerinde en başta uygun adsorban miktarını bulmak için sabit sıcaklık ve pH'da, farklı miktarda ( $300 \mathrm{mg}, 500 \mathrm{mg}$ $700 \mathrm{mg}$ ve $900 \mathrm{mg}$ ) adsorban madde (sepiyolit) eklenerek karıştırılmış ve optimum adsorban miktarı belirlenmiştir. Daha sonra ise optimum $\mathrm{pH}^{\prime} 1$ belirlemek için, $24^{\circ} \mathrm{C}$ 'de ve farklı $\mathrm{pH}$ 'larda deneyler yapılmıştır. Borun adsorpsiyonu $\mathrm{pH}$ 3-5-7-9-11 aralığında incelenmiştir. $\mathrm{Bu}$ nedenle $100 \mathrm{~mL}$ 'lik erlenmayere, 700 ppm derişiminde bor (III) iyonları içeren çözeltiden alınmış ve üzerine $500 \mathrm{mg}$ sepiyolit eklemesi yapılmıştır. Farklı derişimlerdeki $\mathrm{NaOH}$ ve $\mathrm{HNO}_{3}$ çözeltilerinden uygun miktarlarda kullanılarak, karışımın $\mathrm{pH}$ 'sı istenilen $\mathrm{pH}$ değerlerine ayarlanmış, 30 dakika boyunca manyetik karıştırıcı 
(Heidolph MR 3001K) ile 140 rpm'de karıştırılarak, WTW series inoLab $730 \mathrm{pH}$ metresi ile $\mathrm{pH}$ ölçümleri gerçekleştirilmiştir. Daha sonra karışım $0.2 \mu \mathrm{m}$ gözenek boyutlu agilent şırınga filtre ile süzülüş, süzüntüler ise uygun oranlarda seyreltilerek bu örnekler Spektroquant Prove 600 UV-VIS kullanılarak analiz edilmişlerdir. Tüm testler iki kez tekrarlanarak çoğaltılmıştır. Cihaz sonuçları mg L-1 cinsinden verilmektedir.

Bor iyonu adsorpsiyon verileri aşağıdaki eşitlikler yardımıyla hesaplanmıştır.

Adsorpsiyon $(\%)=\left[\left(\mathrm{C}_{0}-\mathrm{Ce}\right) / \mathrm{C}_{0}\right] * 100$

Burada;

Adsorpsiyon (\%), adsorpsiyonun yüzde verimini;

$\mathrm{C}_{0}$, bor iyonlarının başlangıçtaki derişimini ( $\left.\mathrm{g} \mathrm{L}^{-1}\right)$;

$\mathrm{Ce}$, adsorpsiyon sonrasındaki bor iyonları derişimini

( $\mathrm{g} \mathrm{L}^{-1}$ ) göstermektedir.

\section{BULGULAR}

Sepiyolit adsorbanının bor adsorpsiyonundaki davranımı, $\mathrm{pH}(3,5,7,9,11)$ ve adsorban miktarı (300 mg, $500 \mathrm{mg}, 700 \mathrm{mg}$ ve $900 \mathrm{mg}$ ) değişkenleri ve değerleri için araştırılmıştır. $\mathrm{Bu}$ parametrelerin adsorpsiyonu nasıl etkiledikleri araştırılmış ve elde edilen sonuçlar literatürdeki veriler ile karşılaştırmalı olarak olarak verilmiştir.

Birçok değişken adsorpsiyonda önem teşkil etmektedir. Hangi parametrelerin ne şekilde etkili olduğunun bilinmesi adsorpsiyon işleminde oldukça gereklidir. $\mathrm{Bu}$ değişkenler genellikle adsorbanın, adsorpsiyon ortamının ve adsorbatın özellikleri olarak belirtilmektedir.

Adsorpsiyon olayının gerçekleştiği ortamda bulunan katı adsorban miktarı, adsorpsiyon olayını etkileyen en önemli değişkenlerden bir tanesidir. Bu çalışmada diğer adsorpsiyon deneylerinde kullanılacak adsorban madde miktarına temel oluşturması açısından, sepiyolit adsorbanının madde miktarının etkisi araştırılmıştır. Deneyler adsorban miktarlarını değiştirmek şartıyla, sabit başlangıç çözelti derişiminde (700 ppm $\left.\mathrm{H}_{3} \mathrm{BO}_{3}\right)$ yapılmış ve sonuçlar Şekil $1^{\prime} \mathrm{de}$ verilmiştir. Adsorpsiyon deneyleri $24^{\circ} \mathrm{C}$ olan laboratuvar sıcaklığında ve farklı $\mathrm{pH}(3,5,7,9$, 11) değerlerinde 30 dakika süreyle 140 rpm'de sürekli çalkalanmak suretiyle yapılmıştır. Aktif yüzey alanları adsorban madde miktarının artmasıyla artmaktadır. $\mathrm{Bu}$ nedenle aktif kısımların artması sonucu, giderilmesi istenilen unsurlarm daha fazla miktarda adsorplanması zaten beklenilen bir durum olmaktadır.

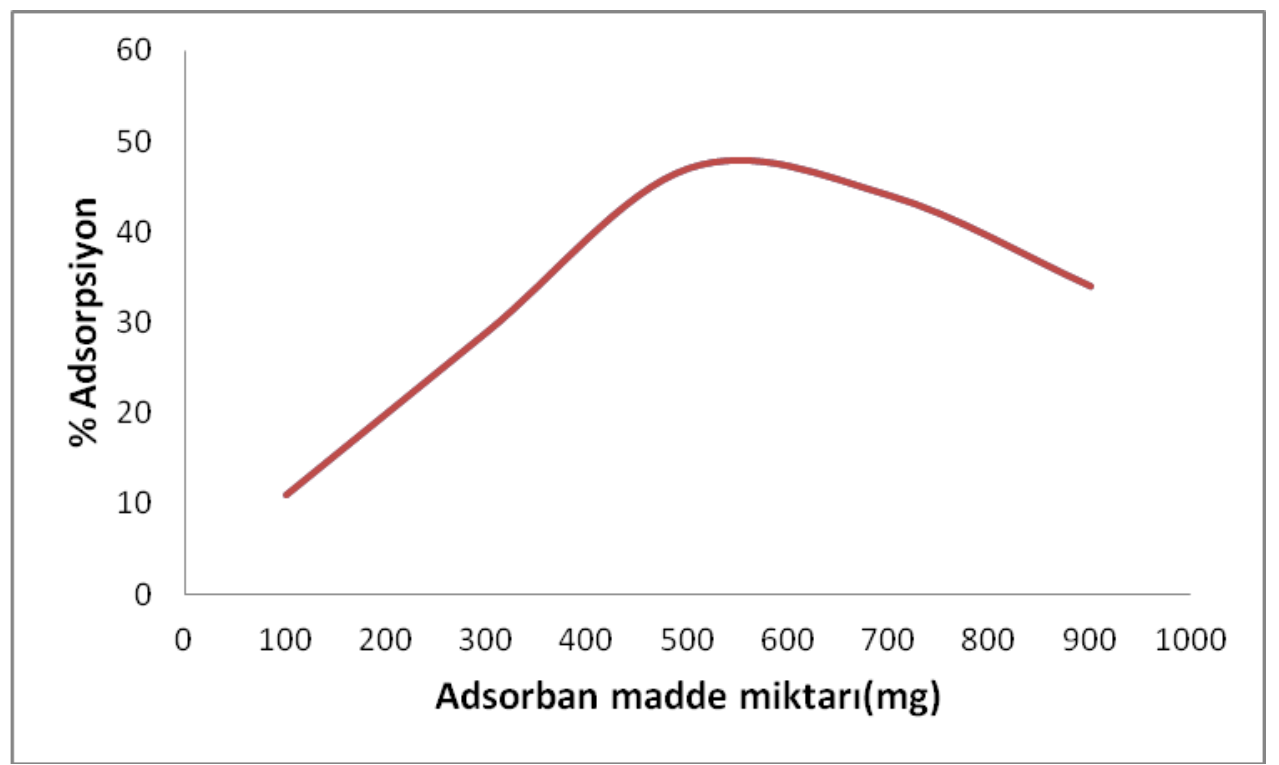

Şekil 1. Adsorpsiyon ile Boronun Uzaklaştırılmasında Adsorban Miktarının Etkisi

Şekil 1‘de, pH=9 değeri için, sepiyolit adsorbanının miktarının artışıla adsorpsiyon verimi (\%) belirli bir miktara kadar artmış, belirli bir değerden sonra ise sepiyolit ilavesi önemli bir değişim oluşturmamıştır. Şekil 1'de belirlenen deneysel şartlar sağlandığında, $500 \mathrm{mg}$ adsorban madde miktarından sonra adsorpsiyon önemli ölçüde azalmıştır. Burada neredeyse bir denge durumuna ulaşıldı $\breve{g ̆}_{1}$ fark edilmektedir. Bundan sonraki deneysel çalışmalarda ise $500 \mathrm{mg}$ adsorban madde miktarının kullanılması uygun bulunmuştur.

Adsorpsiyon olayını etkileyen en önemli değişkenlerden birisi bor iyonlarının farklı $\mathrm{pH}$ ortamlarında farklı iyonik yapıya dönüşebilmesinden ötürü ortamın pH değeridir. Bu amaç ile adsorban olarak kullanılan sepiyolitin bor iyonunu adsorplama davranımı farklı $\mathrm{pH}$ değerleri için araştırılmıştır. Borun giderimi, borik asitin $\mathrm{pH}$ ile kontrol edilebilen 
$\mathrm{B}(\mathrm{OH})_{4}^{-}$ve $\mathrm{B}(\mathrm{OH})_{3}$ yapılarından dolayıdır. Ana bileşenin $\mathrm{B}(\mathrm{OH})_{3}$ olduğu düşük $\mathrm{pH}$ değerlerinde $\mathrm{OH}^{-}$ ve $\mathrm{B}(\mathrm{OH})_{4}^{-}$grupları ortamda azdır. Bu sebep ile $\mathrm{B}(\mathrm{OH})_{3}$ ün düşük afinitesinden nedeniyle düşük $\mathrm{pH}$ değerlerinde bor giderimi daha az oranlarda meydana gelmektedir. $\mathrm{B}(\mathrm{OH})_{4}^{-}$gelişimine bağll olarak ortamdaki pH'nın arttırılması, bor giderimini arttırmaktadir. Bunun nedeni $\mathrm{B}(\mathrm{OH})_{3}$ iyonunun afinitesinin $\mathrm{B}(\mathrm{OH})_{4}$ "den daha az olmasıdır. Böylece pH değerinin artışına bağlı olarak bor adsorpsiyonu artmakta ve Şekil 2'de de görüldüğü gibi belirli bir $\mathrm{pH}$ değerinde maksimum değere ulaşmaktadır.
$\mathrm{Bu}$ tutum, sepiyolitin borik asitle adsorpsiyonunda da görülmektedir. Ortam asidik olduğunda borik asit $\mathrm{B}(\mathrm{OH})_{3}$ formunda bulunmaktadır, bu nedenle adsorpsiyon verimi daha düşük olmaktadır.

Deneyler sabit adsorban miktarı $(500 \mathrm{mg})$, sabit sıcaklık $\left(24^{\circ} \mathrm{C}\right)$, sabit başlangıç çözelti derişimi $(700$ $\left.\mathrm{ppmH}_{3} \mathrm{BO}_{3}\right)$ ve sabit adsorpsiyon süresinde $(30$ dakika) yapılmıştır. Borik asit çözeltisine $\mathrm{HNO}_{3}$ ve $\mathrm{NaOH}$ çözeltisi eklenerek, başlangıç çözelti derişimi değişmeyecek şekilde çözeltilerin $\mathrm{pH}$ değerleri ayarlanmıştır.

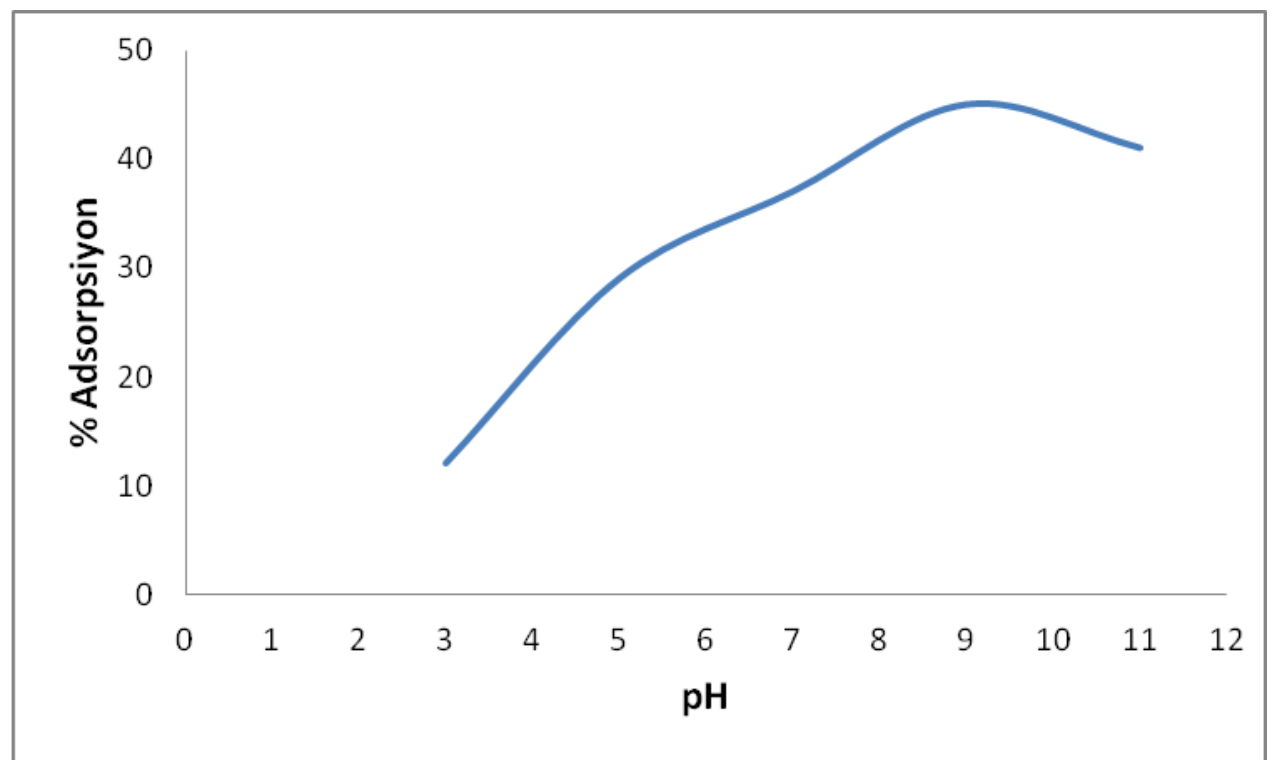

Şekil 2. Farklı pH Değerlerinde Sepiyolit Adsorbanının Bor İyonunu Adsorpsiyonu

Şekil 2 incelendiğinde, adsorpsiyon veriminin düşük $\mathrm{pH}$ değerlerinde düşük olduğunu, $\mathrm{pH}$ değeri arttıkça adsorpsiyon veriminin $\mathrm{pH}=9^{\prime}$ a kadar artış göstediği saptanmıştır. Adsorpsiyon verimi $\mathrm{pH}=9$ ‘da \% 47 verim ile en yüksek değere sahip olmuştur. $\mathrm{pH}=11$ ‘de ise \% 41 adsorpsiyon verimi ile bir düşüş saptanmıştır.

$\mathrm{pH}=9$ değerinde en yüksek adsorpsiyon gerçekleşmiştir. $\mathrm{pH}=9$ değerinden sonra adsorpsiyon verimi $\mathrm{pH}$ değeri artışına bağlı olarak önemli bir miktarda azalma görülmektedir. $\mathrm{pH}$ değeri arttırıldığında, bilindiği üzere borat iyon derişimi $\mathrm{pKa}=9.2$ değerine yakın değerlerde artmakta ve adsorpsiyon maksimum düzeyde gerçekleşmektedir.

\section{TARTIŞMA ve SONUÇ}

$\mathrm{Bu}$ çalışmada, endüstriyel işlemler sonucunda açığa çıkan atık sudaki borun adsorpsiyonu sağlanarak, atık suların toksik etkilerinin dolaylı olarak giderilmesi amaçlanmıştır. $\mathrm{Bu}$ amaca ulaşabilmek için ortam $\mathrm{pH}^{\prime}$ 'nın ve adsorban miktarının adsorpsiyona olan etkileri incelenmiştir.

Adsorban olarak kullanılan sepiyolitin; adsorplama yeteneğinin fazla olması, kolay ve bol bulunabilmesi, ucuz olması gibi nedenlerden ötürü endüstride sıklıkla kullanılması tavsiye edilmektedir. Bu çalışma sepiyolitin boru adsorplayabildiğini ortaya koymuştur. Adsorpsiyonda, adsorban miktarındaki artış ile bağlantılı olarak, adsorplanan madde miktarı 500 mg'a kadar artarak devam etmiş, sonraki adsorban ilavelerinde önemli bir değişime uğramamıştır.

Adsorpsiyon verimi düşük $\mathrm{pH}$ değerlerinde düşük olup, $\mathrm{pH}$ 9‘a kadar $\mathrm{pH}$ değeri arttırıldıkça adsorpsiyon verimi artmış, bu değerden sonra ise $\mathrm{pH}$ değerinin artışına bağlı olarak, önemli bir azalma olduğu belirlenmiştir. Bor çözeltisinin $\mathrm{pH}$ değerinin bor (III) iyonu adsorpsiyonunu etkilediği ve adsorpsiyon kapasitesinin $\operatorname{artan} \mathrm{pH}$ ile $\operatorname{arttığ1}$ gözlemlenmiştir. $\mathrm{B}(\mathrm{OH})_{4}^{-}$artışına bağlı olarak ortamdaki pH'nin arttırılması, borun adsorpsiyonunun artmasina neden olmaktadir. Bunun tersi durumunda ise, ortam asidik olduğunda borik asit $\mathrm{B}(\mathrm{OH})_{3}$ formunda bulunmaktadır, bu da adsorpsiyon veriminin daha düşük olmasına sebebiyet vermektedir. Sonuç olarak; adsorpsiyon için en uygun $\mathrm{pH}$ değeri 9 olarak bulunmuştur. 
Yüzey alanının artması sebebiyle, adsorban miktarının artması bor giderimini arttırmaktadır. Belli bir değerden sonra ise adsorban miktarının artması bor gideriminde bir değişime neden olmamaktadır. Adsorban miktarı olarak $500 \mathrm{mg}$ sepiyolit, $\mathrm{pH}=9$ ve $24{ }^{\circ} \mathrm{C}$ olarak optimum koşullar tespit edilmiştir. $\mathrm{Bu}$ şartlarda ise bor adsorpsiyonu \%47 olarak bulunmuştur. Adsorban madde miktarının arttırılmasıyla, aktif yüzey alanları arttırılmış ve borun daha fazla miktarda adsorplanması sağlanmıştır.

Sonuç olarak; çevre bakımından olumsuz etkileri olan bor ağır metalinin sepiyolit ile gideriminde, adsorpsiyonun başarılı bir metot olduğu kanaatine ulaşılmıştır.

\section{KAYNAKLAR}

Bai YS, Hunt CD 1996. Dietary boron enhances efficacy of cholecalciferol in broiler Chicks. Journal of Trace Elements in Experimental Medicine, 9: 117-132.

Brauner K, and Preisinger A 1956. Strüktür und Entstehung des Sepioliths. Tschermaks mineralogische und petrographische Mitteilungen, 6: 120-140.

Brown PH, Bellaloui N, Wimmer MA 2002. Boron in plant biology. Plant Biol, 4: 205-223.

Çalık A 2002. Türkiye`nin Bor Madenleri ve Özellikleri. Mühendis ve Makine Dergisi, 508: 3641.

Çalık A 2004. Türkiye'nin Bor Madenleri ve Özellikleri. II. Uluslararası Bor Sempozyumu, 2325 Eylül, Eskişehir.

Çengeloglu Y, Tor A, Arslan G, Ersoz M, Gezgin S 2007. Removal of boron from aqueous solution by using neutralized red mud. Journal of Hazardous Materials, 142: 412-417.

Dean JA 1987. Lange's handbook of chemistry. New York: McGraw-Hill.

Fort DJ, Stover EL, Strong PL, Murray FJ, Keen CL 1999. Chronic feeding of a low boron diet adversely affects reproduction and development in Xenopus laevis. J Nutr, 129(11): 2055-2060.

Holleman AF, Wiberg E 2001. Inorganic chemistry, New York:Academic Press.

Hunt CD 2003. Dietary boron: an overview of the evidence for its role in immune function. J Trace Elem Exp Med, 16: 291-306.

Kayadan V, Pehlivan V, Çaglayan B, Türedi S 2004.
Düsük Tenörlü kolemanit cevherinin Kalsinasyon Yöntemi ile Zenginleştirilmesi. II Uluslararası Bor Sempozyumu Bildiriler Kitabı, 23-25 Eylül, Eskisehir, 65-69.

Keren R, Bingham FT 1985. Boron in water, soils, and plants. Adv Soil Sci, 1: 229-276.

Nable RO, Bañuelos GS, Paull JG 1997. Boron toxicity. Plant and Soil, 193(1-2): 181-198.

Nagy B and Bradley WF 1955. The Structural Scheme of Sepiolite. Am Mineral, 40: 885-892.

Öztürk N, Köse TE 2008. Boron removal from aqueous solutions by ionexchange resin: Batch studies. Desalination, 227: 233-240.

Fail PA, Chapin RE, Price CJ, Heindel JJ 1998. General, reproductive, developmental, and endocrine toxicity of boronated compounds. Reproductive Toxicology, 12(1): 1-18.

Power PP and Woods WG 1997. The chemistry of boron and its speciation in plants. Plant Soil, 193: 1-13.

Priscilla MC 1998. Beta-Hydroxy-BetaMethylbutyrate (HMB). Nutritional Supplements for Weight Gain. Sports Science Exchange, 11: 6872.

Rainey CJ, Nyquist LA, Christensen RE, Strong PL, Dwight Culver B, Coughlin JR 1999. Daily boron intake from the American diet. Journal of the American Dietetic Association, 99: 335-340.

Sabah E, Çelik MS 1998. Sepiyolit oluşumu, özellikleri, kullanım alanları. İnci Ofset, Afyon.

Uygan D, Çetin Ö 2004. Bor'un Tarımsal ve Çevresel Etkileri: Seydisuyu Su Toplama Havzası. II. Uluslararası Bor Sempozyumu, 23-24 Eylül, Eskişehir

WHO 2003. World Health Organization Guidelines for drinking water quality: Boron. World Health Organization, Geneva.

Waggott A 1969. An investigation of the potential problem of increasing boron concentrations in rivers and water courses. Water Res, 3: 749- 765.

$\mathrm{Xu}$ Y, Jiang JQ 2008. Technologies for Boron Removal. Ind Eng Chem Res, 47: 16-24.

Yingkai X, Lan W 2001. The effect of $\mathrm{pH}$ and temperature on the isotopic fractionation of boron between saline brine and sediments. Chemical Geology, 171: 253-261.

Zhimin G, Jiafei Lv, Peng B, Xianghai G 2016. Boron removal from aqueous solutions by adsorption - A review. Desalination, 383: 29-37. 